\title{
Trends in HIV-related Stigma in the General Population During the Era of Antiretroviral Treatment Expansion: An Analysis of 31 Sub-Saharan African Countries
}

\author{
Brian T. CHAN ${ }^{a, b,{ }^{*}}$ and Alexander C. TSA ${ }^{b, c, d}$
}

aBrigham and Women's Hospital, Boston, MA, USA 'Harvard Medical School, Boston, MA, USA 'Massachusetts General Hospital, Boston, MA, USA dMbarara University of Science and Technology, Mbarara, Uganda

\begin{abstract}
Background-HIV-related stigma is associated with increased risk-taking behavior, reduced uptake of HIV testing, and decreased adherence to antiretroviral therapy (ART). Although ART scale-up may reduce HIV-related stigma, the extent to which levels of stigma in the general population have changed during the era of ART scale-up in sub-Saharan Africa is unknown.
\end{abstract}

Methods-Social distance and anticipated stigma were operationalized using standard HIVrelated stigma questions contained in the Demographic and Health Surveys (DHS) and AIDS Indicator Surveys (AIS) of 31 African countries between 2003-2013. We fitted multivariable linear regression models with cluster-correlated robust standard errors and country fixed effects, specifying social distance or anticipated stigma as the dependent variable and year as the primary explanatory variable of interest.

Results-We estimated a statistically significant negative association between year and desires for social distance ( $b=-0.020 ; \mathrm{p}<0.001 ; 95 \%$ Confidence Interval [CI], -0.026 to -0.015 ) but a statistically significant positive association between year and anticipated stigma $(b=0.023$; $\mathrm{p}<0.001 ; 95 \% \mathrm{CI}, 0.018-0.027)$. In analyses stratified by HIV prevalence above or below the sample median, declines in social distancing over time were more pronounced among countries with a higher HIV prevalence.

Conclusion-Concomitant with ART scale-up in sub-Saharan Africa, anticipated stigma in the general population increased despite a decrease in social distancing towards people living with HIV (PLHIV). Although ART scale-up may help reduce social distancing toward PLHIV, particularly in high-prevalence countries, other interventions targeting symbolic or instrumental concerns about HIV may be needed.

\section{Keywords}

Stigma; Africa; trends

\footnotetext{
"Corresponding author: Brian T. Chan, MD; Brigham and Women's Hospital; 15 Francis St, PBBA-4; Boston, MA 02115; USA; Phone: 617-732-8881; Fax: 617-732-6829; bchan@ partners.org.

Conflicts of Interest: The authors declare no conflicts of interest.
} 


\section{Introduction}

Although the concept of treatment as prevention has generated optimism that an AIDS-free generation is within reach ${ }^{1}$, the success of this approach hinges upon early diagnosis and linkage to care for people living with HIV (PLHIV) ${ }^{2}$. Unfortunately, people continue to present for HIV care at late stages of disease ${ }^{3}$. HIV-related stigma has been recognized as a major impediment to HIV prevention and treatment efforts ${ }^{4,5}$. HIV-related stigma within the general population has been associated with reduced uptake of voluntary counseling and testing ${ }^{6,7}$ and increased sexual risk-taking behavior ${ }^{8,9}$. HIV-related stigma in the general population may manifest as negative attitudes toward PLHIV (including desires for social distance $^{10}$ ) or as specific behaviors targeting PLHIV, either through word or action (enacted stigma $^{11,12}$ ). In addition to experiencing enactments of stigma, PLHIV—or their caregivers and family members, who may be subjected to courtesy stigma ${ }^{13}$-may perceive negative attitudes and expect rejection from others (regardless of whether these enactments actually occur), a phenomenon known as anticipated stigma ${ }^{10,14}$. Anticipated stigma encompasses not only fears of unwanted disclosure but also the anticipated consequences of unwanted disclosure. PLHIV may also internalize and accept these negative attitudes as valid; this internalized stigma has been associated with poor mental health status ${ }^{15,16}$, reduced likelihood of serostatus disclosure ${ }^{17,18}$, and poorer adherence to antiretroviral therapy $(\text { ART })^{19,20}$.

Despite increasing recognition of the negative effects of HIV-related stigma, there remains a dearth of evidence-based interventions available to reduce stigma either for individuals or at the level of the population ${ }^{21-23}$. However, ART scale-up itself may reduce HIV-related stigma in the general population. Although it has been argued that taking ART might increase the risk of PLHIV being subjected to stigma enactments (because the consistent behaviors required for ART adherence may make it more difficult to hide one's serostatus ${ }^{24}$ ), this concern may ultimately be outweighed by ART-related improvements in physical health and HIV-related symptom burden that reduce the extent to which PLHIV internalize stigmatizing beliefs ${ }^{25,26}$ and restore or maintain their economic viability and inclusion within social networks ${ }^{27,28}$. These positive changes, in turn, weaken the symbolic and instrumental associations ${ }^{29}$ between HIV and economic incapacity, social isolation, and imminent death ${ }^{30,31}$. Consistent with the contact hypothesis put forth by Allport ${ }^{32}$, this theoretical effect of ART scale-up on HIV-related stigma should be most evident in countries with high HIV prevalence. In these settings, individuals would have more opportunities for personal contact with PLHIV, including PLHIV who have benefited from the restorative effects of ART, resulting in decreased fear and branding of PLHIV as the "other" 33,34 .

The extent to which levels of HIV-related stigma in the general population have changed during the current era of ART scale-up in sub-Saharan Africa is not well understood. In particular, the effect of ART scale-up on different dimensions of stigma in the general population, namely anticipated stigma ${ }^{35,36}$ and desires for social distance ${ }^{10}$, is unclear. A recent analysis of Ugandan data from 2006-2011 revealed a decrease over time in social distancing but an increase in anticipated stigma ${ }^{37}$. In a cross-country analysis of 18 African countries, an association was found between ART coverage and declines in HIV-related 
stigma in the general population; this association appeared to be more pronounced in countries with relatively high HIV prevalence ${ }^{38}$. However, that ecological analysis was restricted to country-level data and used a composite measure of HIV-related stigma that did not distinguish between anticipated stigma and desires for social distance. Therefore, the extent to which there is divergence in these different aspects of stigma in other African countries is unknown.

Understanding the extent to which different dimensions of HIV-related stigma have actually changed during ART scale-up is important for policymakers. For example, finding decreases over time in both anticipated stigma and social distancing would provide another impetus for further ART expansion and potentially lessen the need for other anti-stigma interventions. However, if one or both dimensions of stigma were to decrease only modestly or actually increase, it would reinforce the need to develop and implement other population-based interventions against the different types of stigma. To help answer this question, we examined trends in stigma in sub-Saharan Africa using individual-level data from the Demographic and Health Surveys (DHS) and AIDS Indicator Surveys (AIS), distinguishing between anticipated stigma and desires for social distance. Our primary aim was to understand temporal trends in anticipated stigma and desires for social distance in the general population of sub-Saharan Africa during an era of ART scale-up. We also sought to understand whether these trends differed according to national HIV prevalence.

\section{Methods}

Our analysis focused on countries in sub-Saharan Africa during 2003 to 2013, which was a period of significant ART scale-up supported by the Global Fund for AIDS, Tuberculosis and Malaria and the US President's Plan for AIDS Relief ${ }^{39,40}$. We extracted individual-level data on HIV-related stigma from the DHS and AIS, which are nationally representative, population-based surveys conducted approximately every five years in over 90 low- and middle-income countries ${ }^{41}$. The standardization of DHS/AIS questions, including those on HIV-related stigma, allows for the analysis of temporal trends in attitudes and behaviors within countries ${ }^{37}$ as well as comparative analyses across countries ${ }^{38,42}$. Details of DHS/AIS sampling procedures are available on the DHS website and in published country reports ${ }^{43}$. We pooled individual-level data from respondents aged 15 to 49 years into a single dataset, using a de-normalization procedure to take into account the survey weights for each country-level datase ${ }^{41}$. For the stratified analyses, we extracted country-level data on HIV prevalence from the UNAIDS AIDSInfo online database ${ }^{44}$. UNAIDS estimates HIV prevalence in countries using a modeling approach which incorporates annual antenatal clinic data as well as data from nationally-representative population-based surveys that include blood testing ${ }^{45,46}$.

\section{Measures}

The primary outcomes of interest were desires for social distance and anticipated stigma. The DHS/AIS contain three questions which measure desires for social distance: 1) "If a member of your family became sick with AIDS, would you be willing to care for her or him in your own household?"; 2) "Would you buy fresh vegetables from a shopkeeper or vendor 
if you knew that this person had the AIDS virus?"; and 3) "In your opinion, if a female teacher has the AIDS virus but is not sick, should she be allowed to continue teaching in the school?" Negative responses to these questions reflect a preference to maintain social distance ${ }^{10}$, often motivated by instrumental concerns about casual transmission or by the symbolic association of HIV with perceived deviance ${ }^{29}$. We defined a respondent as having a desire for social distance if he/she had a negative response to at least one of these three questions. The DHS/AIS contains one question on anticipated stigma, "If a member of your family got infected with the AIDS virus, would you want it to remain a secret or not?" Positive responses to this question reflect fear of disclosing a hypothetical HIV infection ${ }^{36}$, in particular the expectation of negative consequences (e.g., rejection or condemnation) were a family member's HIV-positive status revealed to others ${ }^{35}$.

Socio-demographic variables (age, gender, educational attainment, marital status, household asset wealth ${ }^{47,48}$, and employment status) were included in the regression models as potential confounders of the relationship between time and stigma. Furthermore, we included an HIV knowledge variable equal to the number of correct responses to six questions about HIV prevention and transmission (see Supplementary Digital Content 1). Adjusting for these variables ensured that the observed trends were not due to compositional changes in the sample over time or changing trends in important socioeconomic indicators such as education. The DHS/AIS data were then merged with country-level UNAIDS data on HIV prevalence. For cases in which the DHS data spanned two years (e.g. 2012-2013), we abstracted HIV prevalence from the first year of the survey. There were seven countries with a DHS/AIS survey in 2003 (Burkina Faso, Ghana, Kenya, Madagascar, Mozambique, Nigeria, and Tanzania), but UNAIDS data on HIV prevalence were not available prior to 2004. For these countries, we matched the UNAIDS data from 2004 with the DHS/AIS from 2003.

\section{Statistical analysis}

We used descriptive statistics to characterize the sample. For the primary analysis, we fitted linear regression models with cluster-correlated robust standard errors ${ }^{49-51}$ and country fixed effects, alternately specifying social distance or anticipated stigma as the dependent variable, and year as the primary explanatory variable of interest. A statistically significant regression coefficient was considered evidence that stigma was changing over time. As a sensitivity analysis, an ordinal composite variable for social distance was also created, with values ranging from zero (answering no to all three questions) to three (answering yes to all three questions); this variable was then used in a multivariable ordered logistic regression model. The 2003 Burkina Faso DHS had only one question on social distancing (about caring for a family member with AIDS), so respondents to this DHS were excluded from the analyses on social distance.

To obtain an adjusted estimate for the regression coefficient for year, we fitted multivariable linear regression models with cluster-correlated robust standard errors and country fixed effects, adjusting for socio-demographic variables and HIV knowledge. We then conducted a stratified analysis by national HIV prevalence (using a threshold of $2.9 \%$, the median prevalence in 2013 across the countries represented in our study sample) to assess whether 
temporal trends in HIV-related stigma differed by HIV prevalence. To formally test the hypothesis that the year trends were different, we fitted a multivariable regression model to the entire sample and included a product term for the interaction between national HIV prevalence (greater than or equal to $2.9 \%$ vs. less than $2.9 \%$ ) and year. All analyses were performed using Stata software (Version 13.1, StataCorp, College Station, TX).

\section{Results}

715,319 women and 334,256 men from 31 sub-Saharan African countries, comprising 63 DHS/AIS, were included in the analyses. Survey refusal rates among men and women in the DHS/AIS were typically less than $10 \%$, and no survey had a refusal rate more than $20 \%$. DHS/AIS respondent characteristics are stratified by gender in Table 1. Across all surveys, $51 \%$ of respondents endorsed at least one measure of social distance, while $50 \%$ endorsed anticipated stigma. The Cronbach's alpha for the three social distancing questions was 0.66. Although it is difficult to interpret p-values in light of the large sample size, women appeared to be more likely to endorse anticipated stigma ( $53 \%$ vs. $44 \% ; \chi^{2}=6,300$, $\mathrm{p}=<0.001$ ). Compared to countries with HIV prevalence at or above $2.9 \%$ in 2013, countries with HIV prevalence below 2.9\% in 2013 had a much higher prevalence of social distancing ( $61 \%$ vs. $\left.44 \% ; \chi^{2}=28,000, p=<0.001\right)$ but a similar prevalence of anticipated stigma ( $50.4 \%$ vs. $49.9 \% ; \chi^{2}=21, \mathrm{p}=<0.001$ ). Trends in prevalence of stigma by country (for countries with more than one DHS/AIS survey between 2003 and 2013) are shown in Figures 1 and 2.

We estimated a statistically significant negative association between year and desires for social distance ( $b=-0.020 ; \mathrm{p}<0.001 ; 95 \%$ Confidence Interval $[\mathrm{CI}],-0.026$ to -0.015 ) but a statistically significant positive association between year and anticipated stigma ( $b=0.023$; $\mathrm{p}<0.001 ; 95 \% \mathrm{CI}, 0.018-0.027$ ). Compared to the baseline mean across countries in 2003, these regression coefficients suggest an approximately $4 \%$ relative reduction in prevalence of desires for social distance and 6\% relative increase in prevalence of anticipated stigma with each year. Adjustment for socio-demographic variables and HIV knowledge yielded no substantive changes in these findings (Table 2). The sensitivity analysis using an ordinal composite variable for social distancing did not yield a meaningful difference in statistical significance for year (adjusted odds ratio $[\mathrm{AOR}]=0.903 ;$ 95\% CI, 0.89-0.93) compared with the binary outcome.

In analyses stratified by median national HIV prevalence in 2013, declines in desires for social distance over time were noted in both high and low prevalence countries. The statistical significance and magnitude of the negative association between time and desires for social distance was greater in high prevalence countries $(b=-0.021, \mathrm{p}<0.001 ; 95 \% \mathrm{CI}$, -0.029 to -0.013$)$ compared to low prevalence countries $(b=-0.015 ; \mathrm{p}=0.02 ; 95 \% \mathrm{CI}$, -0.026 to -0.003 ) (Supplementary Digital Content 3), although the interaction term was not statistically significant $(\mathrm{p}=0.33)$. Increases in anticipated stigma of similar magnitude were found in both high $(b=0.025, \mathrm{p}<0.001 ; 95 \% \mathrm{CI}, 0.016-0.033)$ and low $(b=0.022 ; \mathrm{p}<0.001$; 95\% CI, 0.017-0.028) prevalence countries (Supplementary Digital Content 3). 


\section{Discussion}

In this longitudinal, cross-country analysis of data on more than one million persons from 31 sub-Saharan African countries obtained during a period of ART scale-up, we found evidence for an increase in anticipated stigma in the general population despite an apparent decrease in social distancing towards PLHIV. These trends were not explained by compositional changes in HIV knowledge or important socio-demographic variables such as educational attainment. Furthermore, we found evidence for a more substantial decrease over time in social distancing in countries with high HIV prevalence compared to countries with low HIV prevalence, whereas similar increases in anticipated stigma were found in high and low prevalence countries. These findings have important implications for policymakers, as they suggest that ART scale-up alone may be insufficient to effect meaningful improvements in HIV-related stigma, and that further initiatives to counter stigma are likely necessary, such as educational campaigns ${ }^{21,52}$, changes to laws that institutionalize stigma ${ }^{19}$, and livelihood interventions for PLHIV ${ }^{30,31}$.

Our findings support the hypothesis that ART scale-up reduces desires for social distance by improving physical health and reducing HIV-related symptom burden, allowing PLHIV to reintegrate as productive members of society and diminishing the association of HIV with economic incapacity 30,31 and "social death" 53 . That this effect is more evident in highprevalence countries compared to low-prevalence countries lends support to the contact hypothesis put forth by Allport ${ }^{32}$. Despite being one of the foremost theories in prejudice reduction ${ }^{54}$, more field experiments are needed to confirm the findings that have emerged in laboratory-based research ${ }^{55}$. Our findings are consistent with this theory, in that persons in high-prevalence countries should have relatively more opportunities to have personal contact with PLHIV and observe the salubrious effects of ART. However, more studies using experimental, quasi-experimental, or qualitative methods are needed in order to definitively test these hypothesized mechanisms.

Less clear is why anticipated stigma has increased over time in both low- and highprevalence countries while desires for social distance have declined. One possible explanation is social desirability bias; after a decade or more of exposure to HIV knowledge campaigns, people in the general population may increasingly understand how they ought to feel about PLHIV while experiencing no changes in their actual feelings toward PLHIV. Respondents could increasingly feel social pressure to endorse accepting attitudes toward PLHIV without necessarily changing their opinions about fear of disclosure of a family member's hypothetical HIV infection. Alternatively, respondents might feel more accepting toward PLHIV who were infected prior to the educational campaigns of the past decade, yet still harbor negative attitudes toward PLHIV who have more recently been infected (i.e., reflecting a belief that these persons ought to have "known better" than to engage in risky behaviors). Finally, although respondents may actually have changed their personal attitudes towards PLHIV, they may have perceived that others in society have not. Thus, their perceptions of prevailing injunctive and/or descriptive norms ${ }^{56}$ might cause them to persistently have fears of disclosure (whether hypothetical or not) despite changes in their own beliefs. 
Regardless of the veracity of these explanations, it remains uncertain why anticipated stigma would have increased rather than merely failed to decline-a phenomenon that appears to hold true for almost all countries under study (Figure 2). As our analyses adjusted for differential trends in HIV knowledge as well as education and other socio-demographic variables, the reasons for this finding remain unclear. One important consideration is whether ART scale-up has failed to counter, or perhaps has even exacerbated, the symbolic association of HIV with behaviors perceived to be deviant, which may be a driver of anticipated stigma. While providing physical health benefits for PLHIV, ART does little to counter entrenched feelings of blaming or moral outrage in the community. In fact, it has been argued that ART scale-up might actually worsen such feelings and create an "ART stigma" 57 , in that the physical health benefits afforded by ART may be perceived as allowing PLHIV to engage in promiscuous behaviors and spread HIV to others ${ }^{58,59}$. If this is indeed the case, policymakers have a difficult but necessary task at hand: developing and implementing interventions to counter these symbolic drivers of HIV-related stigma that exacerbate risk behaviors and reduce uptake of HIV prevention and testing services.

There are several limitations to our study. First, our measures of social distance and anticipated stigma, which have been used as core indicators by UNAIDS ${ }^{60}$, are self-reports of hypothetical scenarios that could be misconstrued by respondents, rather than validated multi-item scales. Although this limitation has been noted by others ${ }^{61,62}$, this limitation would only bias our estimates (of trends in stigma) if the extent to which respondents misinterpreted the survey questions has systematically changed over time. Over the short time frame of the study, we believe this possibility is unlikely. It is worth noting that the DHS is planning to revise the stigma indicators in future questionnaires, which may enhance their reliability and validity ${ }^{63}$. Second, our study did not include data from South Africa, the country with the world's largest HIV epidemic; nor did our study include longitudinal data on all countries (i.e., some countries only had one DHS/AIS during the period under study). Nevertheless, our study is the most comprehensive analysis to date, including 31 countries and over 1 million individuals. Finally, although our results demonstrate temporal trends in HIV-related stigma, it is likely that other factors besides ART scale-up, such as educational campaigns and other stigma-reduction activities ${ }^{21,64}$, may have been in part responsible for the observed trends. Nevertheless, as discussed above, we believe ART scale-up to be likely the most important factor cutting across all 31 countries under study. Regardless of other potential factors, our overall conclusions remain the same: namely, that ART scale-up is probably beneficial in reducing desires for social distance but that other targeted interventions to reduce HIV-related stigma, particularly related to symbolic concerns over the meaning of HIV, will be needed to help encourage uptake of HIV testing and treatment.

In conclusion, in this longitudinal, cross-country analysis of data from 31 sub-Saharan African countries, we found a decline in social distancing towards PLHIV but increasing anticipated stigma in the general population during a period of ART scale-up. Declines in social distancing appeared to be more pronounced in countries with high HIV prevalence, in support of the theory that more frequent personal contact with PLHIV and the health-giving effects of ART allow for decreased fear, misconceptions, and labeling of PLHIV as the "other." Our findings suggest that ART scale-up may be beneficial for stigma reduction but is unlikely to be a panacea, especially in countries with relatively low HIV prevalence. 
Further study is needed to elucidate the reasons for worsening anticipated stigma in the general population and to develop effective and scalable interventions that target both the symbolic and instrumental drivers of stigma.

\section{Supplementary Material}

Refer to Web version on PubMed Central for supplementary material.

\section{Acknowledgments}

A preliminary version of this analysis was presented at IDWeek, San Diego, CA, USA, October 8, 2015.

Sources of Funding: The authors acknowledge the following sources of support: the KL2/Catalyst Medical Research Investigator Training award (an appointed KL2 award) from Harvard Catalyst | The Harvard Clinical and Translational Science Center (National Center for Research Resources and the National Center for Advancing Translational Sciences, National Institutes of Health Award KL2 TR001100) (Chan) and NIH K23MH096620 (Tsai)

\section{References}

1. Sidibé M, Zuniga JM, Montaner J. Leveraging HIV treatment to end AIDS, stop new HIV infections, and avoid the cost of inaction. Clin Infect Dis. 2014; 59(Suppl 1):S3-S6. DOI: 10.1093/cid/ciu321 [PubMed: 24926030]

2. McNairy ML, El-Sadr WM. Antiretroviral therapy for the prevention of HIV transmission: what will it take? Clin Infect Dis. 2014; 58(7):1003-1011. DOI: 10.1093/cid/ciu018 [PubMed: 24429438]

3. Siedner MJ, Ng CK, Bassett IV, Katz IT, Bangsberg DR, Tsai AC. Trends in CD4 Count at Presentation to Care and Treatment Initiation in Sub-Saharan Africa, 2002-2013: A Meta-analysis. Clin Infect Dis. 2015; 60(7):1120-1127. DOI: 10.1093/cid/ciu1137 [PubMed: 25516189]

4. UNAIDS. Key programmes to reduce stigma and discrimination and increase access to justice in national HIV responses. Available at: http://www.unaids.org/en/media/unaids/contentassets/ documents/document/2012/Key_Human_Rights_Programmes_en_May2012.pdf

5. Grossman CI, Stangl AL. Editorial: Global action to reduce HIV stigma and discrimination. J Int AIDS Soc. 2013; 16(3 Suppl 2):18881. [PubMed: 24242269]

6. Kelly JD, Weiser SD, Tsai AC. Proximate Context of HIV Stigma and Its Association with HIV Testing in Sierra Leone: A Population-Based Study. AIDS Behav. Mar.2015 doi: 10.1007/ s10461-015-1035-9

7. Kalichman SC, Simbayi LC. HIV testing attitudes, AIDS stigma, and voluntary HIV counselling and testing in a black township in Cape Town, South Africa. Sex Transm Infect. 2003; 79(6):442447. [PubMed: 14663117]

8. Pitpitan EV, Kalichman SC, Eaton LA, et al. AIDS-related stigma, HIV testing, and transmission risk among patrons of informal drinking places in Cape Town, South Africa. Ann Behav Med. 2012; 43(3):362-371. DOI: 10.1007/s12160-012-9346-9 [PubMed: 22367752]

9. Delavande A, Sampaio M, Sood N. HIV-related social intolerance and risky sexual behavior in a high HIV prevalence environment. Soc Sci Med. 2014; 111:84-93. DOI: 10.1016/j.socscimed. 2014.04.011 [PubMed: 24768779]

10. Link BG, Cullen FT, Frank J, Wozniak JF. The social rejection of former mental patients: understanding why labels matter. Am J Sociol. 1987; 92:1461-1500.

11. Scambler G, Hopkins A. Being epileptic: coming to terms with stigma. Sociol Health Ill. 1986; 8(1):26-43.

12. Earnshaw VA, Smith LR, Chaudoir SR, Amico KR, Copenhaver MM. HIV stigma mechanisms and well-being among PLWH: a test of the HIV stigma framework. AIDS Behav. 2013; 17(5): 1785-1795. DOI: 10.1007/s10461-013-0437-9 [PubMed: 23456594]

13. Goffman, E. Stigma: Notes on the Management of Spoiled Identity. Englewood Cliffs: PrenticeHall; 1963. 
14. Deacon, H.; Stephney, I.; Prosalendis, S. Understanding HIV/AIDS Stigma: a Theoretical and Methodological Analysis. Cape Town: HSRC. Social Cohesion and Integration Unit (SCI); 2005.

15. Simbayi LC, Kalichman S, Strebel A, Cloete A, Henda N, Mqeketo A. Internalized stigma, discrimination, and depression among men and women living with HIV/AIDS in Cape Town, South Africa. Soc Sci Med. 2007; 64(9):1823-1831. DOI: 10.1016/j.socscimed.2007.01.006 [PubMed: 17337318]

16. Tsai AC, Bangsberg DR, Frongillo EA, et al. Food insecurity, depression and the modifying role of social support among people living with HIV/AIDS in rural Uganda. Soc Sci Med. 2012; 74(12): 2012-2019. DOI: 10.1016/j.socscimed.2012.02.033 [PubMed: 22513248]

17. Norman A, Chopra M, Kadiyala S. Factors related to HIV disclosure in 2 South African communities. Am J Public Health. 2007; 97(10):1775-1781. DOI: 10.2105/AJPH.2005.082511 [PubMed: 17761582]

18. Tsai AC, Bangsberg DR, Kegeles SM, et al. Internalized stigma, social distance, and disclosure of HIV seropositivity in rural Uganda. Ann Behav Med. 2013; 46(3):285-294. DOI: 10.1007/ s12160-013-9514-6 [PubMed: 23690283]

19. Katz IT, Ryu AE, Onuegbu AG, et al. Impact of HIV-related stigma on treatment adherence: systematic review and meta-synthesis. J Int AIDS Soc. 2013; 16 (3 Suppl 2):18640. [PubMed: 24242258]

20. Boyer S, Clerc I, Bonono C-R, Marcellin F, Bilé P-C, Ventelou B. Non-adherence to antiretroviral treatment and unplanned treatment interruption among people living with HIV/AIDS in Cameroon: Individual and healthcare supply-related factors. Soc Sci Med. 2011; 72(8):1383-1392. DOI: 10.1016/j.socscimed.2011.02.030 [PubMed: 21470734]

21. Stangl AL, Lloyd JK, Brady LM, Holland CE, Baral S. A systematic review of interventions to reduce HIV-related stigma and discrimination from 2002 to 2013: how far have we come? J Int AIDS Soc. 2013; 16(3 Suppl 2):18734. [PubMed: 24242268]

22. Coates TJ, Kulich M, Celentano DD, et al. Effect of community-based voluntary counselling and testing on HIV incidence and social and behavioural outcomes (NIMH Project Accept; HPTN 043): a cluster-randomised trial. Lancet Glob Health. 2014; 2(5):e267-e277. DOI: 10.1016/ S2214-109X(14)70032-4 [PubMed: 25103167]

23. Jürgensen M, Sandøy IF, Michelo C, Fylkesnes K, ZAMACT Study Group. Effects of home-based voluntary counselling and testing on HIV-related stigma: findings from a cluster-randomized trial in Zambia. Soc Sci Med. 2013; 81:18-25. DOI: 10.1016/j.socscimed.2013.01.011 [PubMed: 23422056]

24. Makoae LN, Portillo CJ, Uys LR, et al. The impact of taking or not taking ARVs on HIV stigma as reported by persons living with HIV infection in five African countries. AIDS Care. 2009; 21(11): 1357-1362. DOI: 10.1080/09540120902862576 [PubMed: 20024711]

25. Tsai AC, Bangsberg DR, Bwana M, et al. How does antiretroviral treatment attenuate the stigma of HIV? Evidence from a cohort study in rural Uganda. AIDS Behav. 2013; 17(8):2725-2731. DOI: 10.1007/s10461-013-0503-3 [PubMed: 23670710]

26. Castro A, Farmer P. Understanding and addressing AIDS-related stigma: from anthropological theory to clinical practice in Haiti. Am J Public Health. 2005; 95(1):53-59. DOI: 10.2105/AJPH. 2003.028563 [PubMed: 15623859]

27. Venkataramani AS, Thirumurthy H, Haberer JE, et al. CD4+ cell count at antiretroviral therapy initiation and economic restoration in rural Uganda. AIDS. 2014; 28(8):1221-1226. DOI: 10.1097/ QAD.0000000000000188 [PubMed: 24406678]

28. Campbell C, Skovdal M, Madanhire C, Mugurungi O, Gregson S, Nyamukapa C. "We, the AIDS people...": how antiretroviral therapy enables Zimbabweans living with HIV/AIDS to cope with stigma. Am J Public Health. 2011; 101(6):1004-1010. DOI: 10.2105/AJPH.2010.202838 [PubMed: 21164081]

29. Pryor JB, Reeder GD, Vinacco R, Kott TL. The instrumental and symbolic functions of attitudes towards persons with AIDS. J Appl Soc Psychol. 1989; 19:377-404.

30. Tsai AC, Bangsberg DR, Weiser SD. Harnessing poverty alleviation to reduce the stigma of HIV in Sub-Saharan Africa. PLoS Med. 2013; 10(11):e1001557.doi: 10.1371/journal.pmed.1001557 [PubMed: 24319400] 
31. Tsai AC, Hatcher AM, Bukusi EA, et al. A livelihood intervention to reduce the stigma of HIV in rural Kenya: longitudinal qualitative study. AIDS Behav. Jan.2016 doi: 10.1007/ s10461-015-1285-6

32. Allport, GW. The nature of prejudice. Reading: Addison-Wesley; 1954.

33. Genberg BL, Hlavka Z, Konda KA, et al. A comparison of HIV/AIDS-related stigma in four countries: negative attitudes and perceived acts of discrimination towards people living with HIV/ AIDS. Soc Sci Med. 2009; 68(12):2279-2287. DOI: 10.1016/j.socscimed.2009.04.005 [PubMed: 19427086]

34. Winskell K, Hill E, Obyerodhyambo O. Comparing HIV-related symbolic stigma in six African countries: social representations in young people's narratives. Soc Sci Med. 2011; 73(8):12571265. DOI: 10.1016/j.socscimed.2011.07.007 [PubMed: 21864965]

35. Link BG. Understanding labeling effects in the area of mental disorders: An assessment of the effects of expectations of rejection. Am Sociol Review. 1987; 52:96-112.

36. Wolfe WR, Weiser SD, Leiter K, et al. The impact of universal access to antiretroviral therapy on HIV stigma in Botswana. Am J Public Health. 2008; 98(10):1865-1871. DOI: 10.2105/AJPH. 2007.122044 [PubMed: 18703447]

37. Chan BT, Weiser SD, Boum Y, et al. Persistent HIV-related stigma in rural Uganda during a period of increasing HIV incidence despite treatment expansion. AIDS. 2015; 29(1):83-90. DOI: 10.1097/QAD.0000000000000495 [PubMed: 25268886]

38. Chan BT, Tsai AC, Siedner MJ. HIV Treatment Scale-Up and HIV-Related Stigma in Sub-Saharan Africa: A Longitudinal Cross-Country Analysis. Am J Public Health. 2015; 105(8):1581-1587. DOI: 10.2105/AJPH.2015.302716 [PubMed: 26066939]

39. Bendavid E, Holmes CB, Bhattacharya J, Miller G. HIV development assistance and adult mortality in Africa. JAMA. 2012; 307(19):2060-2067. DOI: 10.1001/jama.2012.2001 [PubMed: 22665105]

40. Bendavid E, Bhattacharya J. The President's Emergency Plan for AIDS Relief in Africa: an evaluation of outcomes. Ann Intern Med. 2009; 150(10):688-695. [PubMed: 19349625]

41. ICF International Inc. Demographic and Health Survey Sampling and Household Listing Manual. Available at: https://dhsprogram.com/pubs/pdf/DHSM4/ DHS6_Sampling_Manual_Sept2012_DHSM4.pdf

42. Tsai AC. Socioeconomic Gradients in Internalized Stigma Among 4,314 Persons with HIV in SubSaharan Africa. AIDS Behav. 2015; 19(2):270-282. DOI: 10.1007/s10461-014-0993-7 [PubMed: 25572833]

43. DHS Program. http://www.dhsprogram.com

44. UNAIDS. AIDSinfo. Available at: http://www.unaids.org/en/dataanalysis/datatools/aidsinfo/

45. Murray CJL, Ortblad KF, Guinovart C, et al. Global, regional, and national incidence and mortality for HIV, tuberculosis, and malaria during 1990-2013: a systematic analysis for the Global Burden of Disease Study 2013. Lancet. 2014; 384(9947):1005-1070. DOI: 10.1016/ S0140-6736(14)60844-8 [PubMed: 25059949]

46. UNAIDS. Methodology-Understanding the HIV estimates. Available at: http://www.unaids.org/en/ media/unaids/contentassets/documents/unaidspublication/2014/

UNAIDS_methodology_HIVestimates_en.pdf

47. Filmer D, Pritchett LH. Estimating wealth effects without expenditure data-or tears: an application to educational enrollments in states of India. Demography. 2001; 38(1):115-132. [PubMed: 11227840]

48. Filmer D, Pritchett L. The effect of household wealth on educational attainment: evidence from 35 countries. Popul Dev Rev. 1999; 25(1):85-120.

49. Rogers WH. Regression standard errors in clustered samples. Stata Technical Bulletin. 1993; 13:19-23.

50. Williams RL. A note on robust variance estimation for cluster-correlated data. Biometrics. 2000; 56(2):645-646. [PubMed: 10877330]

51. Froot KA. Consistent covariance matrix estimation with cross-sectional dependence and heteroskedasticity in financial data. J Financ Quant Anal. 1989; 24:333-355. 
52. Tsai AC, Venkataramani AS. The causal effect of education on HIV stigma in Uganda: Evidence from a natural experiment. Soc Sci Med. 2015; 142:37-46. DOI: 10.1016/j.socscimed.2015.08.009 [PubMed: 26282707]

53. Egrot M. Renaître d'une mort sociale annoncée: recomposition du lien social des personnes vivant avec le VIH en Afrique de l'Ouest (Burkina Faso, Sénégal). Cultures et Sociétés. 2007; 1:49-56.

54. Paluck EL, Green DP. Prejudice reduction: what works? A review and assessment of research and practice. Annu Rev Psychol. 2009; 60:339-367. DOI: 10.1146/annurev.psych.60.110707.163607 [PubMed: 18851685]

55. Pettigrew TF, Tropp LR. A meta-analytic test of intergroup contact theory. J Pers Soc Psychol. 2006; 90(5):751-783. DOI: 10.1037/0022-3514.90.5.751 [PubMed: 16737372]

56. Cialdini RB, Reno RR, Kallgren CA. A focus theory of normative conduct: recycling the concept of norms to reduce littering in public places. J Pers Soc Psychol. 1990; 58(6):1015-1026.

57. Agnarson AM, Masanja H, Ekström AM, Eriksen J, Tomson G, Thorson A. Challenges to ART scale-up in a rural district in Tanzania: stigma and distrust among Tanzanian health care workers, people living with HIV and community members. Trop Med Int Health. 2010; 15(9):1000-1007. DOI: 10.1111/j.1365-3156.2010.02587.x [PubMed: 20636305]

58. Maughan-Brown B. Stigma rises despite antiretroviral roll-out: a longitudinal analysis in South Africa. Soc Sci Med. 2010; 70(3):368-374. DOI: 10.1016/j.socscimed.2009.09.041 [PubMed: 19892454]

59. Roura M, Urassa M, Busza J, Mbata D, Wringe A, Zaba B. Scaling up stigma? The effects of antiretroviral roll-out on stigma and HIV testing. Early evidence from rural Tanzania. Sex Transm Infect. 2009; 85(4):308-312. DOI: 10.1136/sti.2008.033183 [PubMed: 19036776]

60. UNAIDS. National AIDS programmes: a guide to monitoring and evaluation. Available at: http:// www.who.int/hiv/pub/me/pubnap/en/

61. Nyblade, L.; MacQuarrie, K.; Phillip, F.; Kwesigabo, G.; Mbwambo, J.; Ndega, J. Measuring HIV stigma: results of a field test in Tanzania. Washington, DC: US Agency for International Development; 2005. Available at: http://www.icrw.org/files/publications/Working-ReportMeasuring-HIV-Stigma-Results-of-a-Field-Test-in-Tanzania.pdf

62. Yoder, PS.; Nyblade, L. Comprehension of questions in the Tanzania AIDS Indicator Survey. Calverton, Maryland: ORC Macro; 2004. Available at: http://pdf.usaid.gov/pdf_docs/ PNADC460.pdf

63. Moore, M. DHS adds new stigma indicators. Strive. Apr. 2015 http://strive.1shtm.ac.uk/news/dhsadds-new-stigma-indicators

64. UNAIDS. Reducing HIV Stigma and Discrimination: a critical part of national AIDS programmes: a resource for national stakeholders in the HIV response. Available at: http://www.unaids.org/en/ media/unaids/contentassets/dataimport/pub/report/2008/jc1521_stigmatisation_en.pdf 

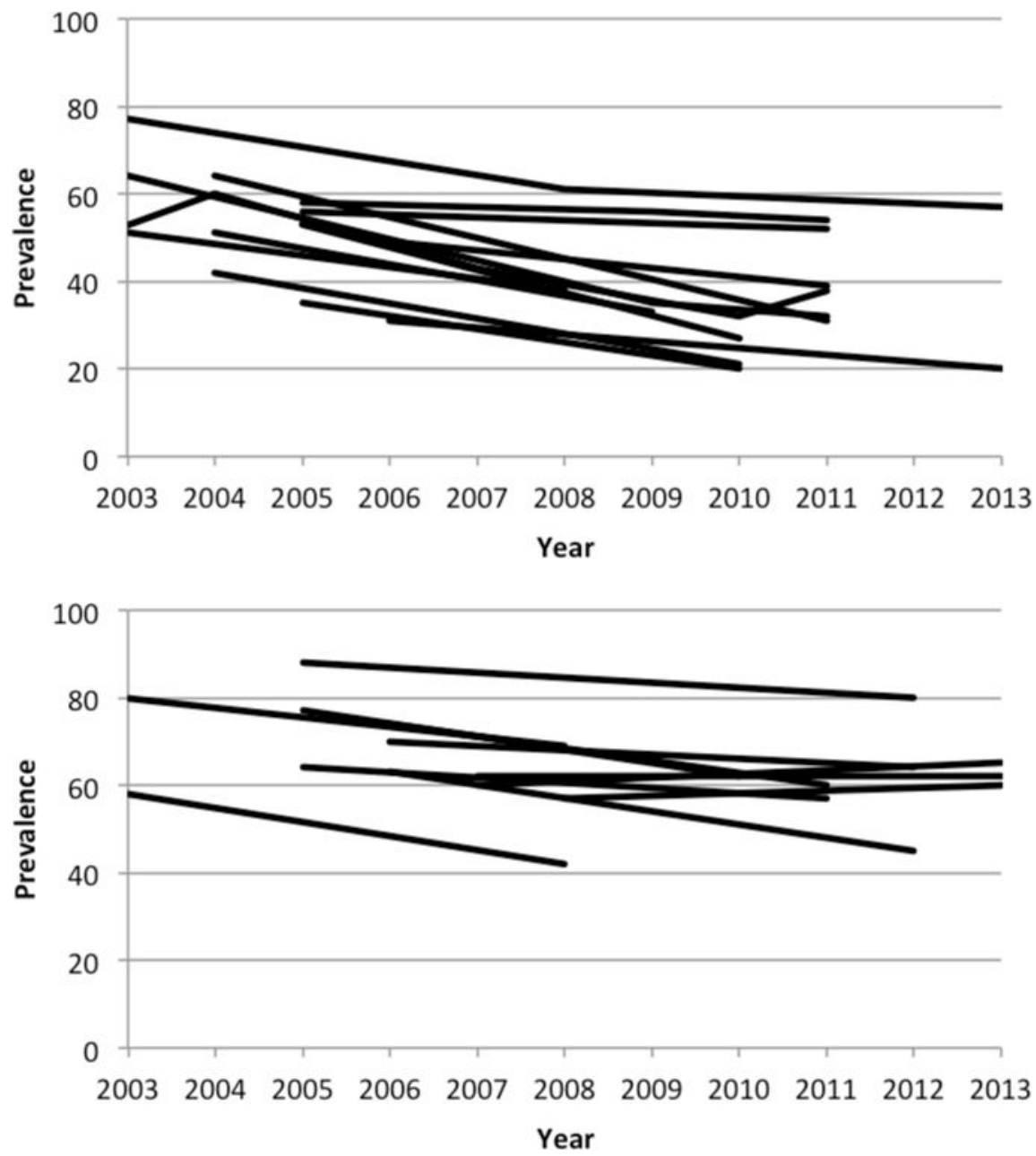

Figure 1.

a: Trends in prevalence of desires for social distance in 13 countries with high HIV prevalence and multiple DHS/AIS, 2003-2013; by country

b: Trends in prevalence of desires for social distance in 11 countries with low HIV prevalence and multiple DHS/AIS, 2003-2013; by country 

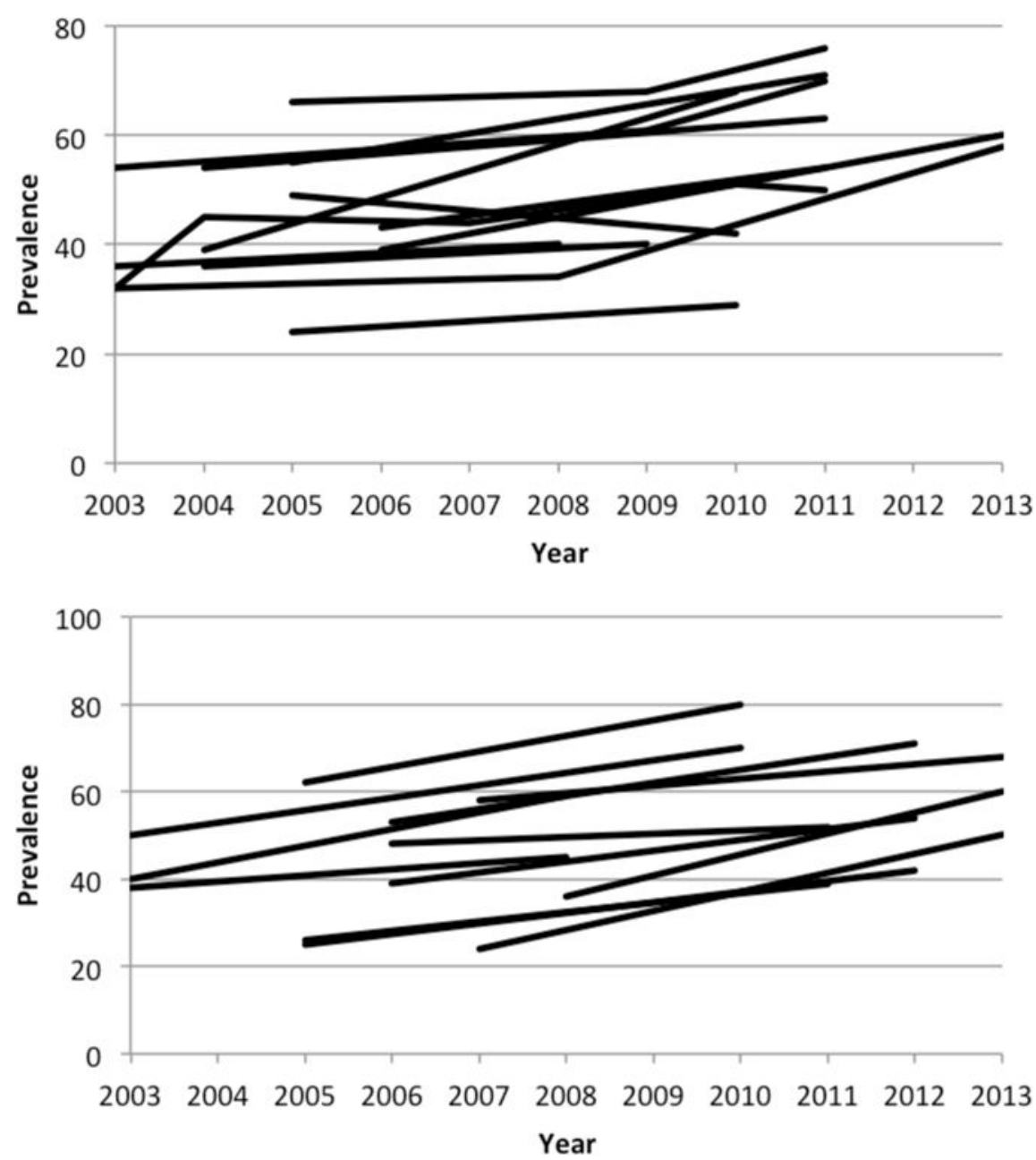

Figure 2.

a: Trends in prevalence of anticipated stigma in 13 countries with high HIV prevalence and multiple DHS/AIS, 2003-2013; by country

b: Trends in prevalence of anticipated stigma in 12 countries with low HIV prevalence and multiple DHS/AIS, 2003-2013; by country 


\section{Table 1}

Characteristics of DHS/AIS participants from 31 sub-Saharan African countries, by gender

\begin{tabular}{|l|l|l|l|}
\hline Characteristic & Overall $(\mathbf{n = 1 , 0 4 9 , 5 7 5 )}$ & Women $(\mathbf{n = 7 1 5 , 3 1 9 )}$ & Men (n=334,256) \\
\hline Age, mean (SD), y & $29.2(10.3)$ & $28.5(9.6)$ & $30.5(11.6)$ \\
\hline Achieved more than primary education & $33 \%$ & $29 \%$ & $42 \%$ \\
\hline Married & $62 \%$ & $66 \%$ & $55 \%$ \\
\hline Household asset index, mean (SD) & (12,520 (163) & $12,023(199)$ & $13,584(283)$ \\
\hline Employed & $63 \%$ & $58 \%$ & $76 \%$ \\
\hline Endorsed desire for social distance & $51 \%$ & $52 \%$ & $50 \%$ \\
\hline Endorsed anticipated stigma & $50 \%$ & $53 \%$ & $44 \%$ \\
\hline
\end{tabular}

All t-tests/chi-square tests for differences by gender yielded p-values of less than 0.001 .

More information about the construction of the household asset index can be found in Filmer \& Pritchett (1999,2001). Information about how the household asset index was specifically operationalized in the DHS/AIS is available at: http://www.dhsprogram.com/topics/wealth-index/Index.cfm 


\section{Table 2}

Regression estimates for the association between year and social distance/anticipated stigma, with covariates

\begin{tabular}{|l|l|l|l|l|}
\hline Variable & \multicolumn{2}{|c|}{ Social distance } & \multicolumn{2}{c|}{ Anticipated stigma } \\
\hline & Adjusted coefficient & $\mathbf{9 5 \%}$ CI & Adjusted coefficient & 95\% CI \\
\hline Year & -0.019 & $(-0.024,-0.013)$ & 0.023 & $(0.018,0.029)$ \\
\hline Female & -0.005 & $(-0.025,0.015)$ & 0.090 & $(0.074,0.106)$ \\
\hline Age, per 10 years & -0.020 & $(-0.029,-0.012)$ & -0.021 & $(-0.032,-0.011)$ \\
\hline Achieved secondary education & -0.144 & $(-0.208,-0.080)$ & -0.019 & $(-0.036,-0.002)$ \\
\hline Married & 0.010 & $(-0.003,0.024)$ & -0.016 & $(-0.027,-0.005)$ \\
\hline Asset index (divided by 10000) & -0.003 & $(-0.007,0.000)$ & 0.001 & $(0.000,0.002)$ \\
\hline Employed & -0.004 & $(-0.011,0.003)$ & -0.008 & $(-0.013,-0.002)$ \\
\hline HIV knowledge & -0.061 & $(-0.080,-0.042)$ & 0.004 & $(-0.005,0.012)$ \\
\hline
\end{tabular}

